\title{
Large intraslab earthquake (2011 April 7, M 7.1) after the 2011 off the Pacific coast of Tohoku Earthquake ( $M$ 9.0): Coseismic fault model based on the dense GPS network data
}

\author{
Yusaku Ohta, Satoshi Miura*, Mako Ohzono ${ }^{\dagger}$, Saeko Kita, Takeshi Iinuma, Tomotsugu Demachi, \\ Kenji Tachibana, Takashi Nakayama, Satoshi Hirahara, Syuichi Suzuki, Toshiya Sato, \\ Naoki Uchida, Akira Hasegawa, and Norihito Umino \\ Research Center for Prediction of Earthquakes and Volcanic Eruptions, Graduate School of Science, Tohoku University, \\ 6-6 Aza-Aoba, Aramaki, Aoba-ku, Sendai 980-8578, Japan
}

(Received June 9, 2011; Revised July 9, 2011; Accepted July 24, 2011; Online published February 21, 2012)

\begin{abstract}
We propose a source fault model for the 2011, April 7, earthquake (M 7.1) deduced from a dense GPS network. The coseismic displacements obtained by GPS data analysis clearly show the spatial pattern specific to intraslab earthquakes, not only in the horizontal components but also the vertical ones. A rectangular fault with uniform slip was estimated by a non-linear inversion approach. The results indicate that the simple rectangular fault model can explain the overall features of the observations. The amount of moment released is equivalent to $M_{\mathrm{w}} 7.17$. The hypocenter depth of the main shock estimated by the Japan Meteorological Agency is slightly deeper than the neutral plane between down-dip compression (DC) and down-dip extension (DE) stress zones of the doubleplaned seismic zone. This suggests that the depth of the neutral plane was deepened by the huge slip of the 2011, $M$ 9.0, Tohoku Earthquake, and the rupture of the thrust $M 7.1$ earthquake was initiated at that depth, although more investigations are required to confirm this idea. The estimated fault plane has an angle of $\sim 60$ degrees from the surface of the subducting Pacific plate. It is consistent with the hypothesis that intraslab earthquakes are thought to be a reactivation of the pre-existing hydrated weak zones produced in the bending process of oceanic plates around outer-rise regions.
\end{abstract}

Key words: Intraslab earthquake, 2011 off the Pacific coast of Tohoku Earthquake, GPS.

\section{Introduction}

A huge earthquake of $M_{\mathrm{w}} 9.0$ occurred beneath the Pacific Ocean in northeastern Japan on March 11, 2011. The event was named by the Japan Meteorological Agency (JMA) as the 2011 off the Pacific coast of Tohoku Earthquake (hereafter the 2011 Tohoku Earthquake). This earthquake generated a gigantic tsunami, which caused a devastating disaster including the loss of more than 15,300 lives as of June 6, 2011. Around the focal area, large earthquakes ( $M 7 \sim 8$ ), named as "Miyagi-oki earthquakes", have been recognized to occur repetitively with a recurrence time of $\sim 37$ years (The Headquarters for Earthquake Research Promotion, 2011). Further discussion on the spatial distribution of interplate coupling during the interseismic period (e.g., Suwa et al., 2006; Hashimoto et al., 2009; Wallace et al., 2009), and also its relationship to the coseismic slip distribution of the 2011 Tohoku Earthquake, is needed. Iinuma et al. (2011) estimated the coseismic slip distribution based

\footnotetext{
* Now at: Earthquake Research Institute, the University of Tokyo.

${ }^{\dagger}$ Now at: Institute of Seismology and Volcanology, Graduate School of Science, Hokkaido University.

Copyright (c) The Society of Geomagnetism and Earth, Planetary and Space Sciences (SGEPSS); The Seismological Society of Japan; The Volcanological Society of Japan; The Geodetic Society of Japan; The Japanese Society for Planetary Sciences; TERRAPUB
}

on the dense cGPS network and concluded that the Miyagioki asperities, which did not slip in the 2005 Miyagi-oki earthquake (M 7.2), were ruptured during the 2011 Tohoku Earthquake.

On April 7, 2011, 14:32 (UTC), one of the largest aftershocks (M 7.1) occurred offshore of the Miyagi prefecture, northeastern Japan. The focal mechanism, estimated by Fnet of the National Research Institute for Earth Science and Disaster Prevention (NIED), suggests a reverse fault-type mechanism with a WNW-ESE compression axis (Fig. 1). This aftershock took place in the source region of the anticipated "Miyagi-oki" earthquake. However, the dip angle of the westward dipping nodal plane is much higher than that of the plate interface in this region. The hypocenter depth of $65.7 \mathrm{~km}$, determined by JMA, is also significantly deeper than the depth of the plate interface there. This seismological evidence strongly suggests that this aftershock was not an interplate earthquake, but an intraslab one.

In this short paper, we propose an $M 7.1$ earthquake fault model based on the onshore GPS displacement data obtained by a dense GPS network consisting of the site operated by Tohoku University and the Geospatial Information Authority of Japan (GSI). We also discuss the relationship between the aftershock distribution and the estimated fault plane. 


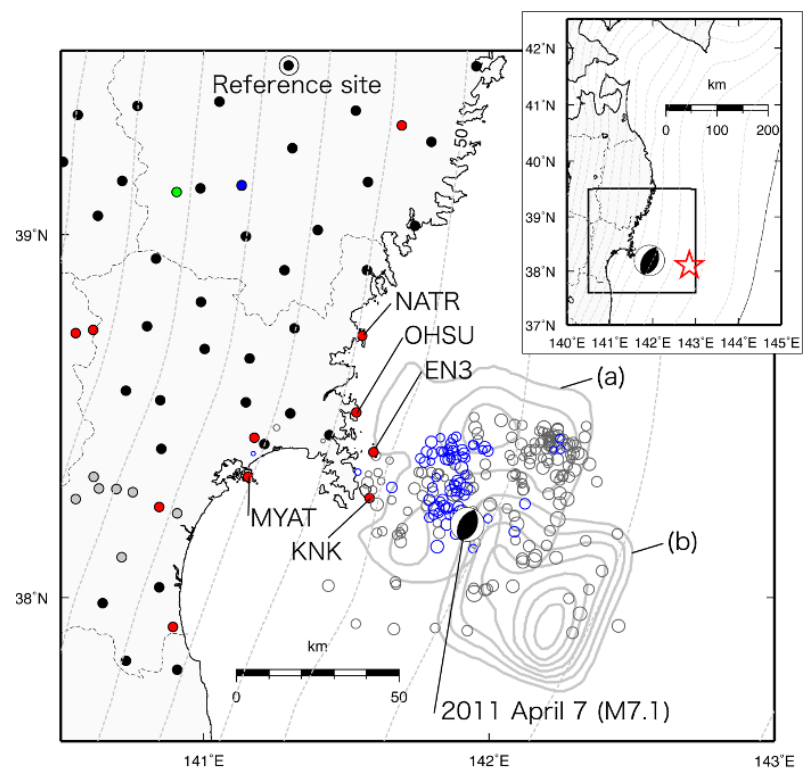

Fig. 1. Map showing GPS sites and the 2011, M 7.1, earthquake. The black rectangle and the red star in the inset map represent locations of the study area and the epicenter of the $2011, M 9$, event determined by JMA, respectively. Small gray circles show the aftershocks determined by the JMA during the period from 11 March to 10 April, 2011. Small blue circles show the aftershocks of the $M 7.1$ event during the period from the 7 April earthquake to 10 April, 2011. The sizes of the circles are proportional to the magnitude of the earthquakes. The black solid circles denote the GEONET sites used in this study. The red, green, and blue solid circles denote the TU, JNES and NAO sites, respectively. The gray solid circles denote the GPS sites for a collaborative research between TU and GSI. The earthquake mechanism is estimated by NIED. The thin dashed line shows the subducting Pacific plate interface isodepth contours compiled by Kita et al. (2010). Each dashed line represents $10-\mathrm{km}$ intervals. Thin black contours denote the slip distribution of past earthquakes (a) 1978 Miyagi-Oki, (b) 1936 Miyagi-Oki estimated by Yamanaka and Kikuchi (2004).

\section{GPS Data and Processing}

The GSI conducts a nationwide GPS network, GEONET, comprising more than 1,200 stations (e.g. Hatanaka, 2003). There are, however, not so many GEONET sites near the coastline and some small offshore islands. Since 1994, Tohoku University (TU) has established new continuous GPS stations in the Tohoku region to complement GEONET and to improve the resolution and detectability of the interplate slip associated with the anticipated Miyagi-oki earthquake (Miura et al., 2004, 2006). We have compiled the continuous GPS data obtained by five different institutions, including TU, GSI, JNES (Japan Nuclear Energy Safety Organization), NAO (The National Astronomical Observatory of Japan) and International GNSS Service (IGS). The GPS carrier phase data were sampled at 1-second or 2-second intervals through dual-frequency receivers at all stations. Data from the TU and JNES networks are transmitted via a broadband network every day except for KNK (Kinkasan Island) and EN3 (Enoshima Island) sites. These two small islands are so close to the focal area of the 2011, $M 9$, earthquake that the GPS data from these sites are definitely invaluable for improving the resolution and reliability of afterslip estimation. However, the electricity and broadband network was cut off soon after the $M 9$ event. Therefore, we installed a VSAT (Very Small Aperture Terminal)
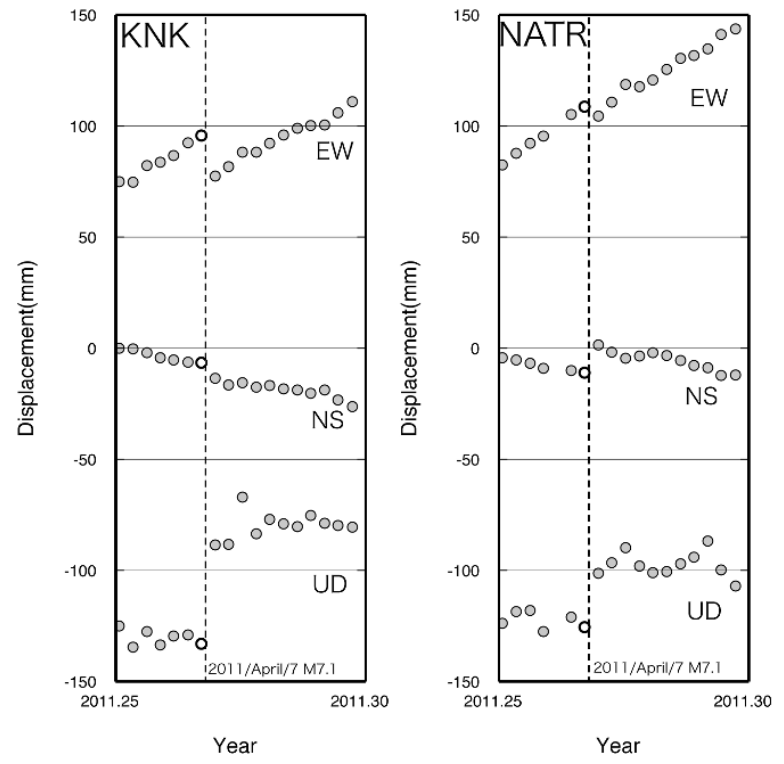

Fig. 2. Time series of daily coordinates at GPS stations with respect to the ITRF2008 reference frame at the KNK and NATR sites. The dashed line denotes the origin time of the April 7, 2011, earthquake. Each gray circle denotes the whole day ( 24 hours) solution. White circles represent the day of the $M 7.1$ event. The data after the mainshock (14:32 on GPS time) was omitted from the processing.

telemetry system shared by Japanese universities, and the WIDESTAR II High-speed Mobile Satellite Communications Service by NTT DOCOMO powered by solar-battery systems, to transmit GPS and short-period seismogram data at KNK on April 1 and EN3 on March 25, respectively. Daily coordinates before, and after, the $M 7.1$ aftershock were estimated using Bernese GPS Software version 5.0 (Dach et al., 2007). In the analysis, we used final precise ephemerides and earth rotation parameters distributed by IGS. Coordinates are based on the ITRF2008 (Altamimi et al., 2011) by constraining the daily coordinates of four IGS sites around Japan (aira, daej, khaj, and yssk). On the day of the $M 7.1$ event (7 April, 2011, the day of year (DOY) 097), to avoid contamination of the displacements before and after the earthquake, we separate the time period of the RINEX data before and after the mainshock (14:32 on GPS time). A number of GPS sites lost power for a few hours immediately after the $M 7.1$ event. Thus, we used the RINEX data only before the $M 7.1$ event on that day, at all sites. Coseismic displacements at each site were defined by the differences between the site coordinates on the DOY, 097 and those on 098. We chose a GEONET site 020909 (Ohbasama), located $130 \mathrm{~km} \mathrm{NNW}$ of the epicenter (shown in Fig. 1), as a reference site to remove the common-mode noise such as the tropospheric error. For the coseismic fault model estimation, we chose 60 GPS sites near the focal area. Figure 1 shows the nearby GPS stations from the focal area. Figure 2 shows an example of the time series from the KNK and NATR sites, with reference to the ITRF2008. The large postseismic deformation following the 2011 Tohoku Earthquake is dominant, especially in the horizontal components directing to the east-southeast. The coseismic steps caused by the $M 7.1$ event also clearly appear in both the horizontal and vertical components. 

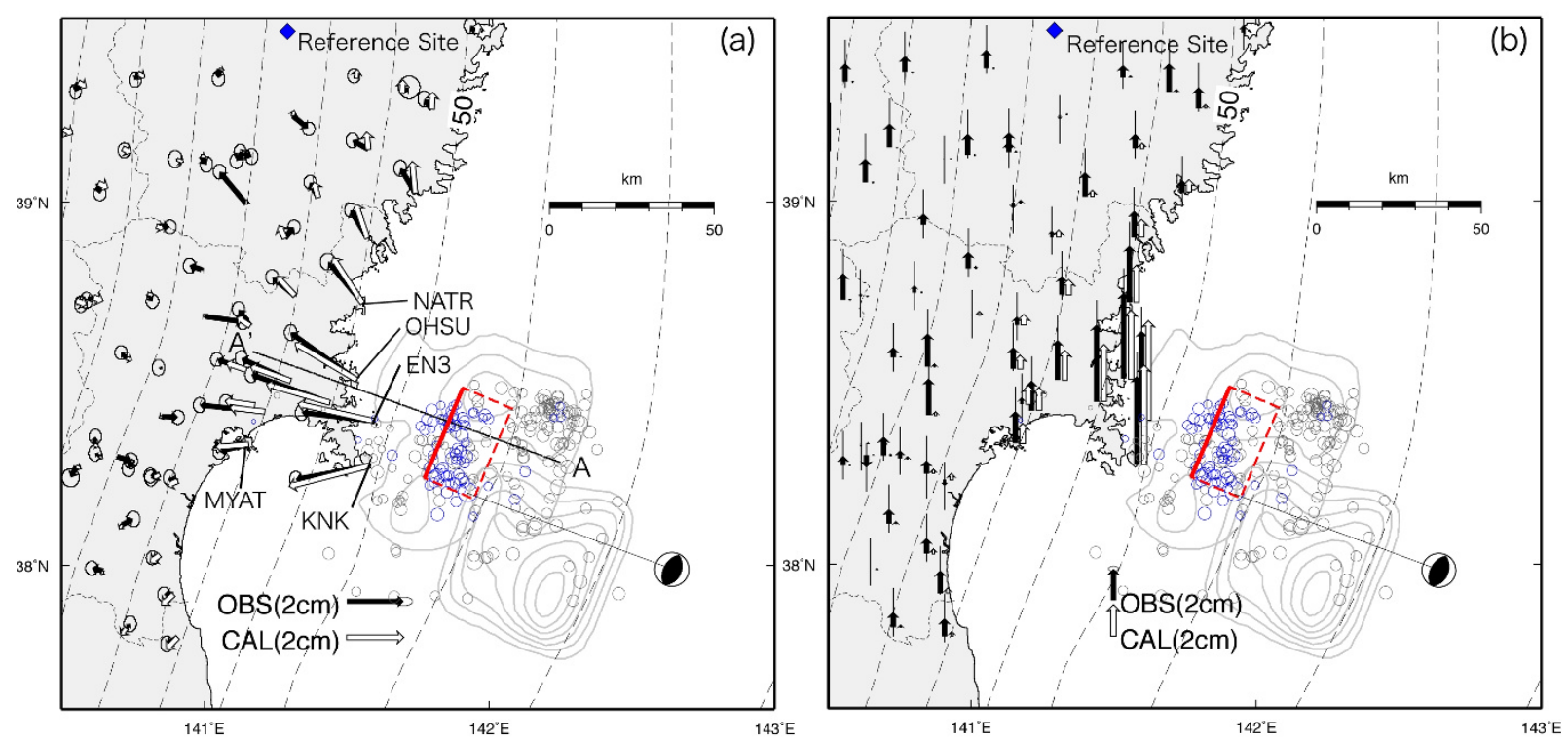

Fig. 3. Distribution of (a) horizontal and (b) vertical components of observed (solid arrows) and calculated (open arrows) coseismic displacements. Ellipses show the associated errors in the estimation of coseismic displacements. The model fault geometry is shown by the red rectangle with broken and solid lines, indicating the lower and upper edges of the faults, respectively. Open arrows indicate calculated displacements from the optimal fault model. Small gray circles show the aftershocks during the period from 11 March to 10 April 2011. Small blue circles show the aftershocks of the M 7.1 event during the period from the 7 April earthquake to 10 April, 2011. The A-A' line (N290E direction) in Fig. 3(a) shows the location of the vertical cross-section shown in Fig. 4.

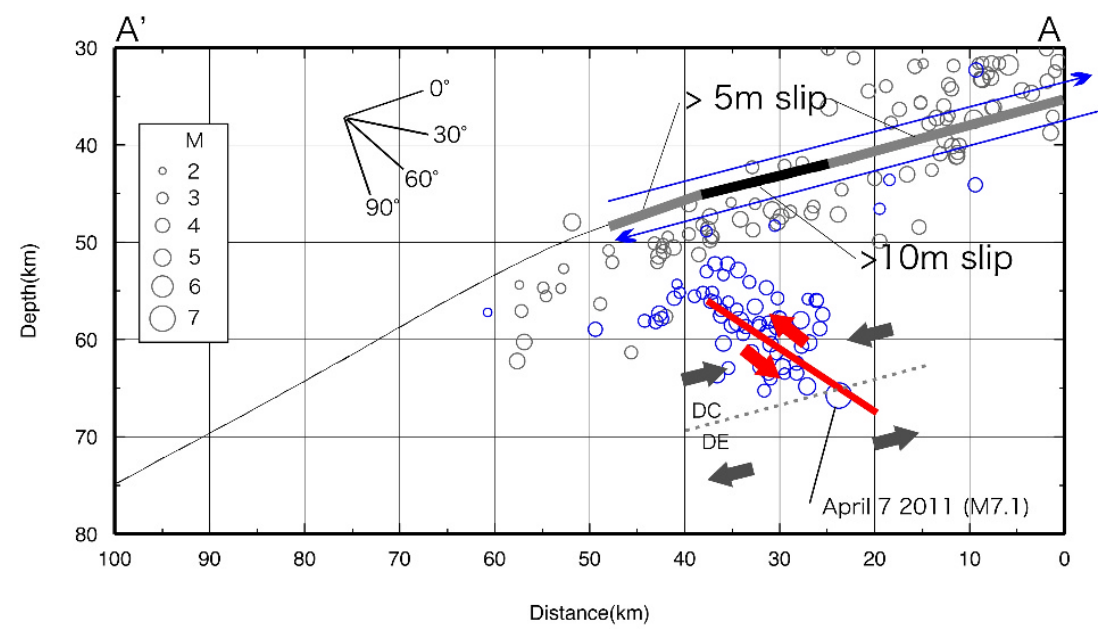

Fig. 4. Location of the estimated fault plane and aftershocks of the $M 9.0$ and $M 7.1$ earthquakes. Along the cross-section is shown by line A-A' in Fig. 3 (a). Small black circles and blue circles represent the aftershocks determined by the JMA between 11 March and 10 April, 2011 , and between the 7 April earthquake and 10 April, 2011, respectively. The red thick line denotes the location of the estimated fault plane of the $M 7.1$ event. The black and gray thick lines along the Pacific plate surface denote portions of the fault plane having 10-m- and 5-m-fault slips (Iinuma et al., 2011), respectively. The blue and red arrows denote the slip directions of the $M 9$ earthquake and the $M 7.1$, April 7, event, respectively. The gray arrows illustrate the background stress field in the subducting plate. The gray dashed line indicates the neutral stress plane by Kita et al. (2010). The protractor indicates the angle from the subducting plate interface.

\section{Results}

\subsection{Coseismic displacement field}

Black arrows in Fig. 3 show the observed coseismic displacement field. It is clear that most of the GPS sites near the coastline were radially displaced from the source area in the horizontal component. By contrast, small (less than $5 \mathrm{~mm}$ ) displacements in the opposite direction occur at the sites far from the epicenter. The maximum horizontal displacement of $26.5 \mathrm{~mm}$ in the WSW direction was recorded at KNK. In the vertical component, most of the GPS sites along the coastline underwent some uplift. It is difficult to detect the systematic vertical signal in the inland area. The maximum uplift signal was $56.4 \mathrm{~mm}$ detected at EN3.

The displacement field strongly suggests that the $M 7.1$ event was not a typical interplate earthquake, because the horizontal displacements must be eastward at GPS sites near the coastline, and the vertical displacement would show subsidence if this was an interpolate event. These observations indicate this earthquake was an intraslab event.

\subsection{Coseismic fault model and aftershock distribution}

The JMA network has determined a precise aftershock distribution of the $M 7.1$ earthquake. Based on the GPS co- 
Table 1. Estimated fault parameters of the optimal rectangular fault. Longitude, latitude, and depth denote the location of the upper-left corner of a rectangular fault plane, looking down from the eastward side.

\begin{tabular}{ccccccccc}
\hline $\begin{array}{c}\text { Longitude } \\
(\text { degree })\end{array}$ & $\begin{array}{c}\text { Latitude } \\
(\text { degree })\end{array}$ & $\begin{array}{c}\text { Depth } \\
(\mathrm{km})\end{array}$ & $\begin{array}{c}\text { Length } \\
(\mathrm{km})\end{array}$ & $\begin{array}{c}\text { Width } \\
(\mathrm{km})\end{array}$ & $\begin{array}{c}\text { Strike } \\
(\text { degree })\end{array}$ & $\begin{array}{c}\text { Dip } \\
(\text { degree })\end{array}$ & $\begin{array}{c}\text { Rake } \\
(\text { degree })\end{array}$ & $\begin{array}{c}\text { Slip } \\
(\mathrm{m})\end{array}$ \\
\hline 141.773 & 38.242 & 56.1 & 30.1 & 20.0 & 23.0 & 35.3 & 97.9 & 2.4 \\
\hline
\end{tabular}

seismic displacement and aftershock distributions, we estimated a rectangular fault model using a non-linear inversion method with a priori information (Matsu'ura and Hasegawa, 1987) in an elastic half space (Okada, 1992). This method can apply constraints of fault parameters as prior information. Estimated parameters sometimes depend on the initial values assumed in the recursive procedure (e.g. Ohta et al., 2008). To estimate all the fault parameters (location, depth, length, width, strike, dip, rake, and slip amount), we assumed initial values based on the F-net mechanism by NIED. We constrained the fault plane location (latitude and longitude, to be within $0.5^{\circ}$ of the initial value), depth (within $10 \mathrm{~km}$ ) and dip angle (within $5^{\circ}$ ) for the recursive procedure, and we also slightly changed the initial value by a trial and error process. The final parameters were defined after obtaining a maximum likelihood solution, which satisfied the fundamental equations defined by Matsu'ura and Hasegawa (1987). It is difficult to distinguish between a southeastward dipping nodal plane, or a northwestward dipping one, only by the GPS data because the calculated displacement at each site shows a similar pattern in the land for both planes. In this study, based on the aftershock distribution showing a southeastward dipping alignment (Fig. 4), we assume the southeastward dipping fault plane is the optimal one. The estimated fault parameters are listed in Table 1.

Figure 3 shows the map-view of the estimated fault plane (red rectangles) and the aftershock distribution (blue circles). The coseismic slip reached up to $2.4 \mathrm{~m}$, an equivalent seismic moment of $7.2 \times 10^{19} \mathrm{~N} \mathrm{~m}\left(M_{\mathrm{w}} 7.17\right.$ with an assumed rigidity of $50 \mathrm{GPa})$. The calculated static stress-drop of this event is approximately 4.0 MPa. Our fault model explains the GPS data well and reproduces the complex spatial pattern of deformation around the coastline. Several GPS sites along the coastline made important contributions to constraining the fault plane. One example are the westward displacements observed at KNK and MYAT, which constrain the location of the southern edge of the fault plane. In a similar way, the vertical displacements at KNK, EN3, OHSU, and NATR are also critical for the fault geometry determination. These GPS sites show uplift signals, while the uplift signals decrease rapidly with the epicentral distance. This suggests that the dip angle of the coseismic fault could be higher, even though there may be some trade off between dip angle, depth of the fault, and slip amount. Assuming this earthquake is an intraslab one, the estimated model in this study explains the observed GPS displacements well. Based on these geodetic results, we conclude that this earthquake is not an interplate earthquake but is an intraslab earthquake.

Figure 4 shows the relationship between the coseismic slip distribution due to the 2011 Tohoku Earthquake by Iinuma et al. (2011) and the location of the M7.1 earth- quake. It is clear that the $M 7.1$ fault plane is located beneath the large coseismic slip of the 2011 Tohoku Earthquake.

The estimated $M 7.1$ fault plane is just located along the aftershock distribution (Fig. 4). The accuracy of the hypocenter depths of the aftershocks might have systematic and/or random errors because the focal area is out of the seismic network. The fault geometry based on the geodetic technique also has some uncertainty for similar reasons. In any case, comprehensive characteristics between the fault plane location and the aftershock distribution show a similarity.

\section{Discussion}

The $M 7.1$ event was followed by its aftershocks along the down dip edge of the estimated fault plane. Within the subducting slab, a neutral stress plane of the doubleplane deep seismic zone (Hasegawa et al., 1978) exists between the upper-plane down-dip compressional (DC) stress regime and the lower-plane down-dip extension (DE) stress regime. Kita et al. (2010) estimated the neutral plane depth from the upper plate interface beneath the Tohoku region based on a stress tensor inversion analysis. They concluded that the neutral plane is located about $22 \mathrm{~km}$ beneath the upper plate interface. The JMA hypocenter of the $M 7.1$ event is located slightly deeper than the neutral plane (Fig. 4). This means that the rupture of the $M 7.1$ event was initiated near the neutral plane, although much of the slip in the event occurred within the down-dip compressional region above. It is surprising that such a large reverse-fault-type intraslab earthquake initiated within the neutral region. At present, we cannot conclude whether the rupture of the April 7 earthquake initiated from the neutral plane or not. Reasons why this reverse intraslab event was initiated within the neutral regions could be (1) the hypocenter depth determined by the JMA is deeper than the true depth, and/or (2) the depth of the neutral stress plane between DC and DE stress became much deeper due to the large slip of the $M 92011$ Tohoku Earthquake along the plate interface. The second scenario may be possible if the down-dip compressional stress was increased by the large slip of the $M 9$ earthquake along the plate interface, since the focal area of the $M 7.1$ event is located just beneath the down-dip edge of the large slip area along the plate interface (see Fig. 4). There is, however, scope for further investigation into the relationship between the neutral stress plane and the starting point of the $M 7.1$ fault slip.

The bending of oceanic plates around trench outer-rise areas in subduction zones generates an extensional stress field, which causes normal faulting in the uppermost part of oceanic plate (Masson, 1991). Recent studies suggest a hypothesis that pre-existing weak, and preferentially hydrated, faults, generated by the normal faulting around the 
trench outer-rise areas before subduction, are responsible for intraslab earthquakes (e.g., Jiao et al., 2000; Ranero et al., 2005; Hino et al., 2009). Normal faults generally have a high dip angle of roughly $\sim 60$ degree measured from the plate interface. The angle between the coseismic fault plane estimated in this study and the subducting plate interface is also $\sim 60$ degrees (Fig. 4). It suggests that this $M 7.1$ intraslab event is a reactivation of a pre-existing outer-rise normal fault, but with a reverse sense of motion due to the changed stress regime after the slab subduction.

\section{Conclusion}

We propose a coseismic fault model for the 2011, April 7, earthquake (M 7.1) deduced from a dense GPS network. The GPS coseismic displacements clearly indicate intraslab earthquake characteristics. The rectangular fault model was estimated by a non-linear inversion approach. The results indicate that a simple rectangular fault model can explain the observations very well, especially at the coastal GPS sites. The amount of moment release was equivalent to $M_{\mathrm{w}} 7.17$, with a coseismic slip of $2.4 \mathrm{~m}$. The geometry of the estimated fault plane is consistent with the aftershock alignments. The hypocenter depth of the event is around the neutral plane between the DC and DE zones. The location of the event may be controlled by a temporal change of the location of the neutral stress plane, which we suggest has been deepened due to stress changes related to the large slip of the 2011 Tohoku Earthquake along the plate interface, although more investigations are required to confirm this idea. The estimated fault plane has an angle of $\sim 60$ degree from the subducting plate interface. This can be interpreted by the hypothesis that intraslab earthquakes are caused by a reactivation of the pre-existing hydrated weak zones produced in the bending process of oceanic plates at the outer-rise zone.

Acknowledgments. We thank the Miyagi Prefectural government for providing us helicopter flights to collect the GPS data from the Kinkasan and Enoshima islands. We thank to the DOCOMO Engineering Inc. for permitting us to use the equipment of the WIDESTAR II High-speed Mobile Satellite Communications Service for GPS data collection. GPS data were provided by GSI and NAO and by a research project conducted by JNES to establish the evaluation techniques of seismogenic faults. We thank Dr. Laura Wallace and Dr. Masayuki Murase for comments that significantly improved the manuscript. We thank Dr. Taku Urabe and Dr. Takeshi Matsushima for helping us to use the VSAT telemetry system. We also thank the staffs of JMA for allowing us to use seismological data. The seismic data analyzed in this study were provided by the seismic networks of the JMA, NIED (Hi-net), and national universities. We used Generic Mapping Tools (Wessel and Smith, 1998) to make figures.

\section{References}

Altamimi, Z., X. Collilieux, and L. Métivier, ITRF2008: an improved solution of the international terrestrial reference frame, J. Geod., doi:10.1007/s00190-011-0444-4, 2011.

Dach, R., U. Hugentobler, P. Fridez, and M. Meindl, User Manual of the Bernese GPS Software Version 5.0: Astronomical Institute, University of Bern, pp. 612, 2007.
Hasegawa, A., N. Umino, and A. Takagi, Double-planed structure of the deep seismic zones in the northeastern Japan arc, Tectonophysics, 47, 43-58, 1978.

Hashimoto, C., A. Noda, T. Sagiya, and M. Matsu'ura, Interplate seismogenic zones along the Kuril-Japan trench inferred from GPS data inversion, Nature Geosci., 2, 141-144, doi:10.1038/NGEO421, 2009.

Hatanaka, Y., Improvement of the Analysis Strategy of GEONET, Bull. Geogr. Surv. Inst., 49, March, 2003.

Headquarters for Earthquake Research Promotion, Longterm evaluations of the Miyagi-oki earthquake, website (http://www.jishin.go.jp/main/chousa/00nov4/miyagi.htm), 2011.

Hino, R., R. Azuma, Y. Ito, Y. Yamamoto, K. Suzuki, H. Tsushima, S. Suzuki, M. Miyashita, T. Tomori, M. Arizono, and G. Tange, Insight into complex rupturing of the immature bending normal fault in the outer slope of the Japan Trench from aftershocks of the 2005 Sanriku earthquake $(\mathrm{Mw}=7.0)$ located by ocean bottom seismometry, Geochem. Geophys. Geosyst., 10, Q07O18, doi:10.1029/2009GC002415, 2009.

Iinuma, T., M. Ohzono, Y. Ohta, and S. Miura, Coseismic slip distribution of the 2011 off the Pacific coast of Tohoku Earthquake ( $M 9.0$ ) estimated based on GPS data-Was the asperity in Miyagi-oki ruptured?, Earth Planets Space, 63, 643-648, 2011.

Jiao, W., P. G. Silver, Y. Fei, and C. T. Prewitt, Do intermediate- and deepfocus earthquakes occur on preexisting weak zones? An examination of the Tonga subduction zone, J. Geophys. Res., 105, 28,125-28,138, 2000 .

Kita, S., T. Okada, A. Hasegawa, J. Nakajima, and T. Matsuzawa, Existence of interplane earthquakes and neutral stress boundary between the upper and lower planes of the double seismic zone beneath Tohoku and Hokkaido, northeastern Japan, Tectonophysics, 496, 68-82, doi:10.1016/j.tecto.2010.10.010, 2010.

Masson, D. G., Fault patterns at outer trench walls, Mar. Geophys. Res., 13, 209-225, 1991.

Matsu'ura, M. and Y. Hasegawa, A maximum likelihood approach to nonlinear inversion under constraints, Phys. Earth Planet. Inter., 47, 179$187,1987$.

Miura, S., T. Sato, A. Hasegawa, Y. Suwa, K. Tachibana, and S. Yui, Strain concentration zone along the volcanic front derived by GPS observations in NE Japan arc, Earth Planets Space, 56, 1347-1355, 2004.

Miura, S., T. Iinuma, S. Yui, N. Uchida, T. Sato, K. Tachibana, and A. Hasegawa, Co- and post-seismic slip associated with the 2005 Miyagioki earthquake (M 7.2) as inferred from GPS data, Earth Planets Space, 58, 1567-1572, 2006.

Ohta, Y., M. Ohzono, S. Miura, T. Iinuma, K. Tachibana, K. Takatsuka, K. Miyao, T. Sato, and N. Umino, Coseismic fault model of the 2008 IwateMiyagi Nairiku earthquake deduced by a dense GPS network, Earth Planets Space, 60, 1197-1201, 2008.

Okada, Y., Internal deformation due to shear and tensile faults in a halfspace, Bull. Seismol. Soc. Am., 82, 1018-1040, 1992.

Ranero, C. R., A. Villaseñor, J. Phipps Morgan, and W. Weinrebe, Relationship between bend-faulting at trenches and intermediate-depth seismicity, Geochem. Geophys. Geosyst., 6, Q12002, doi:10.1029/ 2005GC000997, 2005.

Suwa, Y., S. Miura, A. Hasegawa, T. Sato, and K. Tachibana, Interplate coupling beneath NE Japan inferred from three-dimensional displacement field, J. Geophys. Res., 111, B04402, doi:10.1029/2004JB003203, 2006.

Wallace, L. M., J. Beavan, S. Miura, and R. McCaffrey, Using global positioning system data to assess tectonic hazards, in Volcanic and Tectonic Hazard Assessment for Nuclear Facilities, Chap. 6, 156-175, Cambridge University Press, 2009.

Wessel, P. and W. H. F. Smith, New, improved version of Generic Mapping Tools released, EOS Trans. AGU, 79(47), 579, 1998.

Yamanaka, Y. and M. Kikuchi, Asperity map along the subduction zone in northeastern Japan inferred from regional seismic data, J. Geophys. Res., 109, B07307, doi:10,1029/2003JB002683, 2004.

Y. Ohta (e-mail: ohta@aob.gp.tohoku.ac.jp), S. Miura, M. Ohzono, S. Kita, T. Iinuma, T. Demachi, K. Tachibana, T. Nakayama, S. Hirahara, S. Suzuki, T. Sato, N. Uchida, A. Hasegawa, and N. Umino 